\title{
Zur Entstehung des Reichsfürstentums Liechtenstein
}

\section{On the establishment of the Principality of Liechtenstein}

\author{
Paul Vogt / paul.vogt@li-life.li \\ Director Emeritus of the Liechtensteinisches Landesarchiv
}

\begin{abstract}
The County of Vaduz and the Lordship of Schellenberg were granted imperial immediacy by the Emperor as early as the second half of the 14th century. The rulers were entitled to exercise high jurisdiction ("blood jurisdiction"), which was the core of the rights of a sovereign state. Subsequently, the dynasties changed about every hundred years. The imperial privileges were always transferred to the new rulers and were confirmed by the emperor again and again. At the beginning of the 17th century, the Princes of Liechtenstein received the title of Imperial Princes from the Emperor, but this title alone did not yet give them the right to participate in the Imperial Diet. For this they needed a territory that was placed under the direct ("immediate") authority of the Empire. After decades of repeated efforts, Prince Johann Adam I was able to buy the Lordship of Schellenberg in 1699 and the County of Vaduz in 1712. These two domains were located far from their other possessions in Austria, Moravia and Bohemia. They were economically almost insignificant, but they had the status of imperial immediacy. At the request of Prince Anton Florian of Liechtenstein, Emperor Charles VI united the two domains and elevated them to the Imperial Principality of Liechtenstein. This gave the Princes the right for "seat and vote" on the Imperial Diet, and secured them a distinguished place among the high nobility in Vienna.
\end{abstract}

\section{Keywords}

Princely house of Liechtenstein, Holy Roman Empire of the German Nation, Imperial Diet (Reichstag), imperial Circles (Reichskreise), Swabian Circle (Schwäbischer Kreis), imperial immediacy, Emperor Charles VI (Karl VI.), Prince Johann Adam I., Prince Anton Florian, Imperial Principality of Liechtenstein, Earldom of Vaduz, Domain of Schellenberg, Karl I. von Liechtenstein, Münzkonsortium 
Im Jahre 1719 vereinigte Kaiser Karl VI. auf Wunsch des Fürsten Anton Florian die beiden reichsunmittelbaren Herrschaften Vaduz und Schellenberg zu einem Fürstentum und gab diesem den Namen Liechtenstein. Damit hatten die Fürsten von Liechtenstein ihr Ziel fast erreicht: Sie wollten eine Rangerhöhung und dafür brauchten sie einen Sitz im Reichsfürstenrat. An Land und Leuten zeigten sie kein Interesse. Erst 1842 besuchte erstmals ein Fürst von Liechtenstein sein Minifürstentum.

Im Rahmen des 300-Jahrjubiläums des Fürstentums Liechtenstein entstanden einige Aufsätze, die sich mit der Entstehung des Fürstentums auseinandersetzen, meist allerdings nur aufgrund der bereits vorhandenen Literatur ohne eigene Quellenarbeit. Gewicht hatte vor allem der vom Liechtensteinischen Landesmuseum herausgegebene Sammelband mit zahlreichen Kurzbeiträgen zu einem breiten Spektrum von Themen. ${ }^{1}$ Die folgenden Ausführungen stützen sich vor allem auf die Arbeiten von Katharina Arnegger, die anlässlich des Jubiläums den langen Weg der Fürsten von Liechtenstein zur Erlangung von Sitz und Stimme im Reichsfürstenrat anhand vieler Quellen erforscht und nachgezeichnet hat. ${ }^{2}$

\section{Die lange Suche nach einer reichsunmittelbaren Herrschaft}

Die Bemühungen des Fürstenhauses zum Erwerb eines reichsunmittelbaren Territoriums reichen in das frühe 17. Jahrhundert zurück. Die drei Brüder Karl, Maximilian und Gundaker von Liechtenstein waren starke Persönlichkeiten, denen das fürstliche Haus seinen gesellschaftlichen und wirtschaftlichen Aufstieg zu einem grossen Teil zu verdanken hat. Karl I. (1569-1627) war ein Opportunist, der sich auf veränderte Situationen einstellen konnte und seine Chancen zu nutzen wusste. ${ }^{3}$ Die Meinungen über seine Person gehen bis heute weit auseinander. Er wurde protestantisch erzogen, trat aber 1599 zum katholischen Glauben über, was eine Voraussetzung für eine erfolgreiche Karriere im kaiserlichen Dienst war. Nur ein Jahr nach seiner Konversion wurde er von Kaiser Rudolf II. in die höchsten Ämter berufen, nämlich zum Obersthofmeister und zum Präsidenten des Geheimen Rates. Kaiser Rudolf II. zeichnete ihn mehrfach mit Titeln aus: 1606 erhielt er den Titel „Hoch- und Wohlgeboren“, 1607 das Grosse Palatinat, mit dem ausserordentliche Privilegien verbunden waren (z.B. Erhebungen in den Adelsstand, Verleihung von Wappen). Er stand kurz vor der Erhebung in den Fürstenstand durch Kaiser Rudolf II., als er 1608 im „Bruderzwist im Hause Habsburg“ die Seiten wechselte und Matthias unterstützte. Bei Kaiser Rudolf fiel er in Ungnade und verlor seine Ämter. Karl hatte aber richtig spekuliert: Im Juni 1608 musste Kaiser Rudolf II. hinnehmen,

1300 Jahre Fürstentum Liechtenstein, 1719-2019. Hg. von Rainer Vollkommer (Liechtensteinisches Landesmuseum), Vaduz 2019.

2 Arnegger, Katharina: Das Fürstentum Liechtenstein. Session und Votum im Reichsfürstenrat. Münster 2019.

3 Allgemein zu Fürst Karl I.: Haupt, Herbert: Liechtenstein, Karl I. von. In: Historisches Lexikon des Fürstentums Liechtenstein; online: eHLFL, https://historisches-lexikon.li/Liechtenstein,_Karl_I._von, abgerufen am 26. 3. 2020. 
dass sein Bruder Matthias das Königreich Ungarn, das Erzherzogtum Österreich und die Markgrafschaft Mähren erhielt.

Unmittelbar nach Weihnachten 1608 erhob Erzherzog Matthias in seiner Funktion als ungarischer König Karl I. von Liechtenstein in den erblichen Fürstenstein. Dieser Fürstentitel war offiziell nur in den von Matthias regierten Erblanden von Bedeutung. Der Titel stand am Anfang von weiteren höchsten Titeln und Ehren. 1612 starb Kaiser Rudolf II., Matthias wurde sein Nachfolger. Für Fürst Karl eröffneten sich damit wieder Möglichkeiten in kaiserlichen Diensten.

Kaiser Matthias starb 1619, also zu Beginn des Dreissigjährigen Kriegs. Sein Nachfolger Kaiser Ferdinand II. gilt als ein kriegerischer und kompromissloser Herrscher, der insbesondere mit den böhmischen Aufständischen keine Gnade kannte. Unter Ferdinand II. gelangte Karl von Liechtenstein wieder in die höchsten kaiserlichen Positionen; seine treuen Dienste wurden grosszügig belohnt. Bereits am 23. Juni 1620 verlieh ihm Kaiser Ferdinand II. den Titel „Reichsfürst“.

Ein Schlüsselereignis in der Geschichte des Fürstenhauses bildete der Aufstand der böhmischen Stände. In der Schlacht am Weissem Berg im November 1620 gelang den kaiserlichen Truppen ein entscheidender Sieg. Die Brüder Karl, Maximilian und Gundaker waren an den Ereignissen massgeblich beteiligt. Nach der Schlacht präsidierte Karl I. von Liechtenstein ein Sondergericht, das 27 Anführer der böhmischen Rebellen auftragsgemäss zum Tode verurteilte. Karl leitete auch die Hinrichtung dieser 27 Männer in Prag. 1622 wurde er Vorsitzender eines Konfiskationsgericht, das die vollständige Enteignung von 166 Personen anordnete. Die Güter der Rebellen wurden an Habsburgtreue katholische Adelige verschenkt oder zu günstigen Bedingungen verkauft. Ebenfalls 1622 wurde Karl königlicher Statthalter von Böhmen. Er hatte Einfluss auf die Verteilung der konfiszierten Güter und den Preis - dabei schaute er darauf, dass er und seine Familie nicht zu kurz kamen. Karl I. gilt als grösster Profiteur der Konfiskationen und konnte das Vermögen der Familie massiv vergrössern. ${ }^{4}$

Eine unrühmliche Rolle spielte er bei den Münzverschlechterungen. Darauf kann hier nicht näher eingegangen werden. ${ }^{5}$ Im Kern ging es darum, dass mit kaiserlicher Bewilligung Münzen geprägt wurden, denen weniger Silber beigemischt wurde, als der Nominalwert vorgab. Die Liechtenstein profitierten bei den Käufen von konfiszierten Herrschaften gleich doppelt: Zum einen kauften sie die Herrschaften weit unter ihrem Wert, zum andern bezahlten sie in schlechter Münze. In der Literatur belegt sind die Beispiele Schwarzkosteletz (Kostelec nad Černými lesy) und Ungarisch Ostra und Kromau. ${ }^{6}$

Karl I. hat für das Fürstenhaus sehr viel erreicht: den Besitz vergrössert, den Zugang zum Kaiserhof gepflegt und zahlreiche Titel und Auszeichnungen erhalten. Der Zugang zum Reichsfürstenrat stand noch nicht in seinem Fokus, er wäre ihm trotz

4 Dopsch, Heinz - Stögmann, Arthur: Liechtenstein, von. In: Historisches Lexikon des Fürstentums Liechtenstein; online: eHLFL, https://historisches-lexikon.li/_Liechtenstein,_von, abgerufen am 26. 3. 2020.

5 Dazu ausführlich: Leins, Steffen: Das Prager Münzkonsortium 1622/23. Ein Kapitalgeschäft im Dreißigjährigen Krieg am Rand der Katastrophe. Münster 2012; Frommelt, Fabian: Das Prager Münzkonsortium 1622/23. Jahrbuch des Historischen Vereins für das Fürstentum Liechtenstein 112, 2013, S. 177-185.

6 Arnegger, K.: Session und Votum, S. 34. 


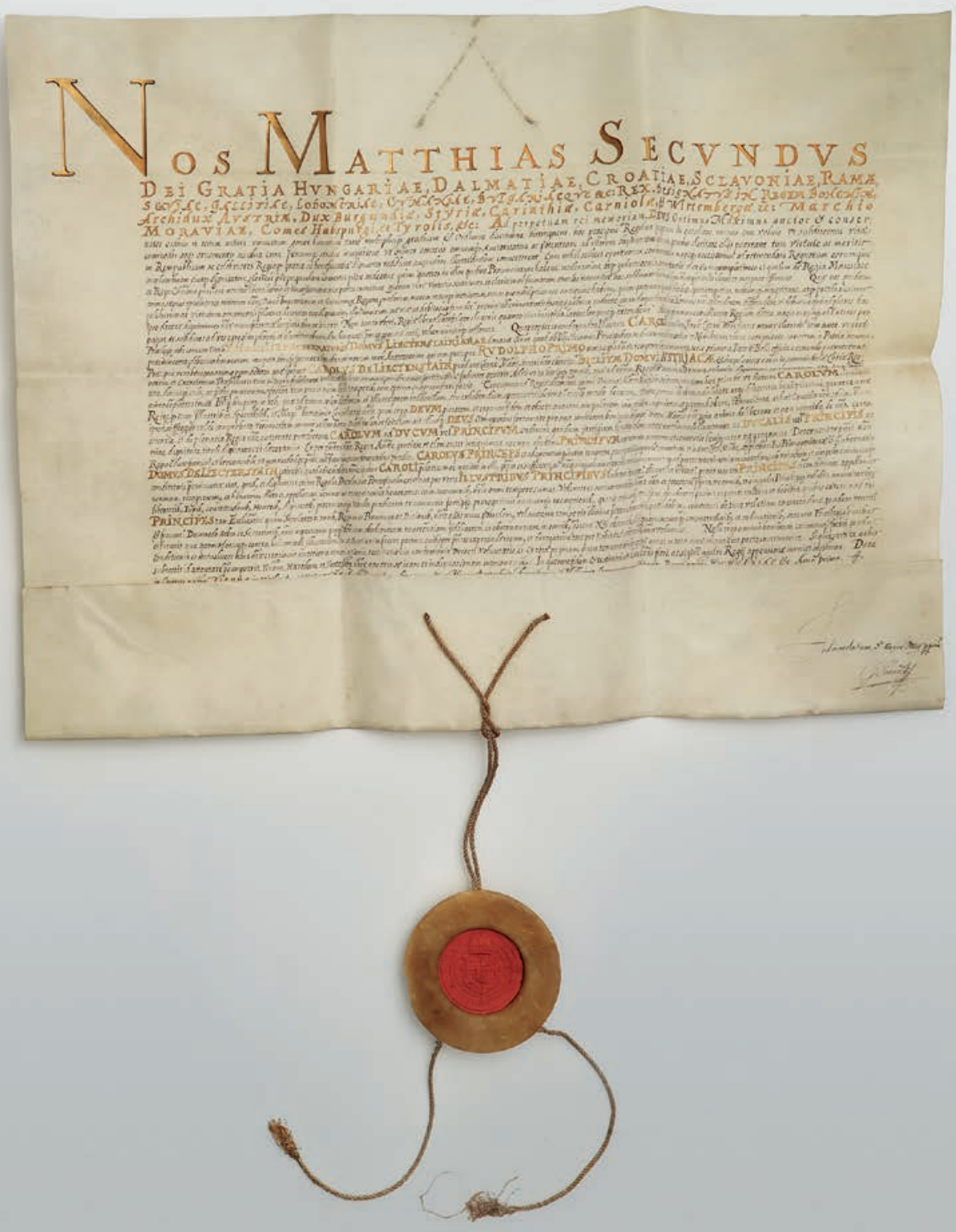

König Matthias erhebt am 20. Dezember 1608 das Haus Liechtenstein in den Fürstenstand. (Foto: LIECHTENSTEIN. The Princely Collections Inv. Nr. UR 1608.12.20.) 
seines Reichsfürstentitels verwehrt geblieben, da er kein Reichsfürstentum besass. 1627 starb er.

Seine Brüder Maximilian und Gundaker waren 1623 von Kaiser Ferdinand ebenfalls mit dem Reichsfürstentitel ausgezeichnet worden. Diese Ehre wurde vom 16. bis zu Beginn des 19. Jahrhunderts einer ganzen Reihe von Fürsten als kaiserliche Auszeichnung zuteil, die über kein reichsunmittelbares Territorium verfügten. ${ }^{7}$ Um die Exklusivität des relativ kleinen Kreises von Reichsfürsten zu wahren, beschloss der Reichstag 1582 in Augsburg, dass nur Fürsten, die zu diesem Zeitpunkt bereits gefürstet waren und ein reichsunmittelbares Territorium besassen, einen Anspruch auf die Reichsstandschaft (das Recht auf Sitz und Stimme im Reichstag) geltend machen konnten. Dieses Recht war an das Territorium gebunden und nicht an die Person des Fürsten. In der Folge kam es zur Unterscheidung von „Altfürsten“ (jenen, die vor 1582 gefürstet wurden) und „Neufürsten“. ${ }^{8}$ Diese Unterscheidung wirkte sich nicht nur auf die Stellung im Reichstag, sondern vor allem auf das Prestige und die Rangordnung der Fürsten aus.

Nach der Erhebung in den Reichsfürstenstand war der Erwerb eines reichsunmittelbaren Territoriums eines der vorrangigen Ziele der Familie Liechtenstein. ${ }^{9}$ Die Fürsten von Liechtenstein befanden sich in einer Konkurrenzsituation zu andern Neufürsten, die ebenfalls ein reichsunmittelbares Territorium zu erwerben suchten. Katarina Arnegger schreibt in diesem Zusammenhang von „einem teilweise demütigenden Präzedenzstreit mit anderen Neufürsten. "10 Durch die Wahlkapitulation von Kaiser Ferdinand III. von 1636 wurden die strengen Zulassungsbedingungen bestätigt. ${ }^{11}$ Danach ergaben sich für neue Fürsten folgende Hürden: Besitz eines reichsunmittelbaren Territoriums, Empfehlung des Kaisers an den Reichstag und zustimmende Beschlüsse des Kur- und Reichsfürstenkollegiums. Weitere Kriterien für eine Aufnahme waren Anciennität sowie Ansehen und Besitz der Familie.

Für den Erwerb eines reichsunmittelbaren Besitzes hat sich Fürst Gundaker besonders engagiert. Er war ein „Höfling“, der nicht weniger als vier Kaisern diente, auch in der Position als Obersthofmeister. Er verfügte über beste Beziehungen in alle Richtungen. Zumindest theoretisch gab es für den Erwerb eines reichsunmittelbaren Territoriums mehrere Möglichkeiten: Die einfachste wäre wohl gewesen, eine Erbtochter zu ehelichen, die ein solches Territorium in die Ehe mitbrachte oder mindestens die Aussicht auf ein entsprechendes Erbe eröffnete. Es gab auch entsprechende Heiratsprojekte, die

7 Vgl. dazu Liste der Erhebungen in den Reichsfürstenstand, Wikipedia, online: https:/ / de.wikipedia.org/wiki/ Liste_der_Erhebungen_in_den_Reichsf\%C3\%BCrstenstand.

8 Haupt, Herbert: Die Neufürsten und ihr Streben nach Reichsunmittelbarkeit. In: 1712 - das Werden eines Landes - 2012. Hg. von Vollkommer, Rainer - Buchel, Donat. Vaduz 2012, S. 116-121.

9 Winkelbauer, Thomas: Fürst und Fürstendiener. Gundaker von Liechtenstein, ein österreichischer Aristokrat des konfessionellen Zeitalters, Wien 1999, S. 321-337.

10 Arnegger, K.: Session und Votum, S. 38.

11 Art. 47 der Wahlkapitulation vom 24. Dezember 1636 bestimmte, dass der Kaiser nur bei Fürsten und Grafen Standeserhöhungen beschliessen durfte, die „wohl meritirt, im Reich geseßen unnd die Mittel haben, denn affectirenden Stanndt pro Dignitate außzuführen." Zitiert nach: Die Wahlkapitulationen der römisch-deutschen Könige und Kaiser 1519-1792. Hg. von Burgdorf, Wolfgang. (Quellen zur Geschichte des Heiligen Römischen Reiches Bd. 1). Göttingen 2015, S. 151. 
jedoch scheiterten. Die zweite Möglichkeit wäre gewesen, vom Kaiser eine reichsunmittelbare Herrschaft zu erwerben. Gundaker machte sich vor allem bei den Grafschaften Burgau (heute in Bayern), Görz (heute in Norditalien) und Cilli (heute in Slowenien) Hoffnungen, doch liess sich auch diese Hoffnung nicht realisieren. Die dritte und am erfolgversprechendste Möglichkeit war, ein reichsunmittelbares Territorium von einem hoch verschuldeten Besitzer zu kaufen. Konkret hatte man die Reichsgrafschaft Ortenburg (heute in Bayern) im Auge. Zu eigentlichen Kaufverhandlungen kam es nirgends.

Eine Möglichkeit wäre auch gewesen, dass der Kaiser einer mediaten Herrschaft die Reichsunmittelbarkeit verliehen hätte. Gundaker erzielte bei einem solchen Versuch immerhin einen Prestigeerfolg: 1633 vereinigte Kaiser Ferdinand II. die beiden Herrschaften Mährisch Kromau (Moravský Krumlov) und Ungarisch Ostra (Uherský Ostroh) zu einem Fürstentum und gab diesem den Namen „Liechtenstein“. Eine solche Vereinigung von Herrschaften und deren Umbenennung auf den Namen des Fürsten war eine im Reich vorher nie dagewesene Auszeichnung, ${ }^{12}$ trotzdem war das neue Fürstentum nur ein Titularfürstentum. Die hoheitlichen Rechte und Regalien (insbesondere das Recht auf Steuern und Kontributionen) blieben beim Markgraf von Mähren. Die ersehnte Erhebung zu einem reichsunmittelbaren Fürstentum blieb eine Illusion. Die Bezeichnung „Fürstentum Liechtenstein “ für die beiden fürstlichen Herrschaften hat sich nie richtig eingebürgert. 1647 wurde der neue Name letztmals verwendet. Der Titel sollte anlässlich einer Erbteilung auf die Herrschaft Ostra allein übertragen werden, diesem Ersuchen stimmte der Kaiser aber nicht zu. In der Folge kehrte man zu den alten Namen für die beiden Herrschaften zurück. ${ }^{13}$

Fürst Karl Eusebius, der Sohn von Fürst Karl I., zeigte sich am Erwerb eines Reichsfürstentums zunächst wenig interessiert, was sein Onkel Gundaker missbilligte. ${ }^{14}$ Offensichtlich schätzte er die Erfolgschancen eines solchen Projekts als gering ein. Im Gegensatz zu seinem Vater und seinem Onkel suchte er nicht in hohe Positionen am kaiserlichen Hof zu kommen. Auch dafür wurde er von Gundaker kritisiert. Er widmete sich lieber der Verwaltung seiner Güter, den schönen Bauten und der Kultur. ${ }^{15}$

Möglicherweise war auch der Ruf seines Vaters, der durch das Münzkonsortium arg lädiert war, eine schwere Hypothek. Nach dem Tod des Fürsten Karl liess Kaiser Ferdinand II. 1628 ein erstes Mal untersuchen, ob sich Fürst Karl mit der Münzverschlechterung widerrechtlich bereichert hatte. Die eingesetzte Kommission fand keine solchen Verfehlungen. Kaiser Ferdinand III. liess dann zehn Jahre später die Vorwürfe erneut untersuchen. Darauf folgte der sogenannte „Liechtenstein-Prozess “, der für Karl Eusebius zweifellos eine enorme Belastung war. Die behaupteten Schadenssummen bewegten sich zwischen 10 und 31 Millionen Gulden, eine fast unvorstellbare Summe. ${ }^{16}$ Die Beweislage

12 Winkelbauer, T.: Fürst und Fürstendiener, S. 345.

13 Winkelbauer, T.: Fürst und Fürstendiener, S. 348.

14 Arnegger, K.: Session und Votum, S. 45.

15 Haupt, Herbert: Fürst Karl Eusebius von Liechtenstein 1611-1684. Erbe und Bewahrer in schwerer Zeit. München 2007, S. 166.

16 Haupt, Herbert: Aufstieg und Konsolidierung. Das Fürstenhaus Liechtenstein im 17. und frühen 18. Jahrhundert. In: Jahrbuch des Historischen Vereins für das Fürstentum Liechtenstein 111, 2012, S. 112. 
war sehr schwierig, die Berechnungen wenig fundiert. Der Prozess zog sich jahrzehntelang dahin. Schliesslich verglich sich Karl Eusebius 1655 mit der Hofkammer gegen die Zahlung von einer Million Gulden. 1665 musste er nochmals 275000 Gulden bezahlen, wofür er dann ein „General-Absolutorium“ erhielt. ${ }^{17}$

Karl Eusebius starb 1684. Sein Sohn Hans Adam I. nahm die Bemühungen zum Erwerb einer reichsunmittelbaren Herrschaft wieder auf. Sein Interesse richtete sich auf die Herrschaften Bludenz und Sonnenberg (heute Bundesland Vorarlberg), auf die Herrschaften Vaduz und Schellenberg sowie auf die Reichsritterschaft Angelberg (in Bayern). ${ }^{18} \mathrm{Zu}$ Verkaufsverhandlungen kam es lediglich mit den Grafen von Hohenems, die hoch verschuldet waren und verkaufen mussten.

\section{Kauf der reichsunmittelbaren Herrschaften Vaduz und Schellenberg durch Hans Adam I.}

Im Jahre1699 konnte Fürst Hans Adam I. die Herrschaft Schellenberg kaufen. Der Verkauf der Grafschaft Vaduz war noch nicht möglich, es war aber bereits klar, dass die Grafen von Hohenems auch Vaduz verkaufen mussten, da sie hoffnungslos verschuldet waren. Hans Adam I. erhielt 1699 ein entsprechendes Vorkaufsrecht. Der Kaufpreis für die Herrschaft Schellenberg wurde auf 115000 Gulden, derjenige für die Grafschaft Vaduz auf 290000 Gulden festgelegt. Gemessen an den zu erwartenden Wirtschaftserträgen (pro Jahr 6000 Gulden aus beiden Herrschaften) waren die beiden Herrschaften massiv überbewertet - doch die erhoffte Rangerhöhung war den Fürsten diese Summe wert. Aus den Erträgen mussten noch die Reichsabgaben - die sogenannten Römermonate und Kammerzieler - bezahlt werden.

Die Hauptschwierigkeit beim Kauf von Vaduz bestand darin, dass die Herrschaften Vaduz und Schellenberg zum hohenemsischen Fideikommiss gehörten, d.h. sie konnten nur unter erschwerten Bedingungen und mit Zustimmung des Kaisers verkauft werden. Bereits die Zustimmung aller Familienmitglieder war ein grosses Problem. Erschwerend kam hinzu, dass Graf Franz Wilhelm III. von Hohenems noch unmündig war und sein Vormund Graf Franz Maximilian von Königsegg-Aulendorf aus verschiedenen Gründen die Verhandlungen verzögerte. ${ }^{19}$ Ein anderes Problem bestand darin, dass der Kaufpreis für Vaduz nicht in bar an den Grafen von Hohenems ausbezahlt, sondern zum Schutz der Familie für den Kauf einer anderen Herrschaft verwendet werden sollte. Diese Möglichkeit bestand bei der böhmischen Herrschaft Bistrau (Bystré u Poličky), die vom hoch verschuldeten Grafen Paul Leopold von Walderode verkauft werden musste. ${ }^{20}$ Bistrau sollte dem Hohenemser Familienfideikommiss eingefügt werden. Die Abwicklung dieses Kaufs war kompliziert und zeitraubend.

\footnotetext{
17 Arnegger, K.: Session und Votum, S. 52-59.

18 Arnegger, K.: Session und Votum, S. 62.

19 Arnegger, K.: Session und Votum, S. 82.

20 Arnegger, K.: Session und Votum, S. 84.
} 
Inzwischen drängte Fürst Hans Adam I. auf die Zulassung in den Schwäbischen Reichskreis. Offenbar war ihm nicht bewusst, dass die Grafen von Hohenems zwar sowohl für die Grafschaft Hohenems wie auch für die Grafschaft Vaduz einen Sitz auf der Grafenbank des Schwäbischen Kreises beansprucht hatten, dass dieser Anspruch aber nicht anerkannt worden war. Anerkannt war nur ihr Anspruch auf einen Sitz, und zwar für ihre Grafschaft Hohenems. Schellenberg war zu klein, um einen solchen Anspruch zu begründen. So musste Hans Adam I. einen Weg finden, um (als nächsten Schritt auf dem Weg zu einem Sitz im Reichsfürstenkollegium) zu einem Sitz auf der Fürstenbank im Schwäbischen Reichskreis zu kommen. Dieser war chronisch verschuldet; so kam man auf die Idee, als Kompensation für das zu kleine Territorium dem Schwäbischen Reichskreis ein zinsloses Darlehen von 250000 Gulden zu gewähren. Dieser Lösung stimmten 1707 beide Seiten zu und Hans Adam I. erhielt einen Sitz auf der Schwäbischen Reichsfürstenbank. Sobald er über ein grösseres reichsunmittelbares Territorium verfügte, sollte dieses zinslose Darlehen zurückbezahlt werden.

1712 konnte schliesslich auch der Kauf der Grafschaft Vaduz abgeschlossen werden. Ein Jahr vorher war Franz Dominik, der einzige Sohn von Fürst Hans Adam I. und der designierte Regierungsnachfolger, gestorben. Dies scheint das Interesse des Fürsten an der Grafschaft Vaduz stark geschwächt zu haben. Zum Schluss willigte er nur noch widerwillig in den Kauf ein, er musste vom Kaiser fast dazu gezwungen werden. ${ }^{21}$ Nur wenige Wochen nach Unterzeichnung des Kaufvertrags starb Fürst Hans Adam I.

\section{Am Ziel dank Fürst Anton Florian}

Aus dem Testament von Fürst Johann Adam I. ergaben sich neue Schwierigkeiten. Sein Nachfolger Fürst Anton Florian, ein Vetter zweiten Grades des Verstorbenen, wurde im Testament übergangen, wo es möglich war. Er erhielt lediglich das Fideikommiss, worauf er gemäss Familienvertrag einen Rechtsanspruch hatte. Der gesamte Allodialbesitz, über den Hans Adam I. frei verfügen konnte, vermachte er seiner Frau, seinen Töchtern und den Prinzen Josef Wenzel und Emanuel. Vaduz und Schellenberg gingen an Josef Wenzel, was zu jahrelangen Rechtsstreitigkeiten in der Familie führte. Mit diesem Testament handelte der Fürst klar gegen die Interessen des Gesamthauses. ${ }^{22}$ Die jahrzehntelangen Bestrebungen, Sitz und Stimme auf dem Reichstag zu erlangen und damit den Aufstieg des Hauses zu krönen, wurden in Frage gestellt, da die neu erworbenen reichsunmittelbaren Besitzungen an eine Nebenlinie gingen. Anton Florian suchte durch Verhandlungen und Gerichtsprozesse die Bestimmungen des Testaments zu revidieren. Er bot auch an, seine böhmische Herrschaft Rumburg (Rumburk), die wirtschaftlich gesehen doppelt so viel Wert war, gegen Vaduz und Schellenberg zu tauschen. Das Haupthindernis war, dass Fürst Josef Wenzel noch minderjährig war und seine Mutter einem Tausch von Vaduz und Schellenberg nicht zustimmte. So verzögerte sich dieser Tausch,

21 Arnegger, K.: Session und Votum, S. 87.

22 Haupt, H.: Aufstieg und Konsolidierung, S. 118. 
bis Josef Wenzel 1718 volljährig wurde. Dann ging es sehr rasch: Josef Wenzel stimmte dem Tausch zu, den der Kaiser bereits genehmigt hatte. Zur Stärkung des familiären Zusammenhalts wurde gleichzeitig eine Hochzeit zwischen Maria Anna, einer Tochter von Anton Florian, und dem jungen Josef Wenzel arrangiert. Maria Anna war damals erst 18, aber bereits seit einem Jahr Witwe. ${ }^{23}$

Fürst Anton Florian machte eine blendende Karriere im Dienst von Kaiser Karl VI. Seine Erziehung war auf eine hohe Laufbahn im Dienst des Kaisers ausgerichtet. Auf seine Tätigkeiten als Erzieher und Obersthofmeister von Erzherzog Karl VI. kann hier nicht eingegangen werden. Von 1703 bis 1711 - während des Spanischen Erbfolgekriegs - begleitete er den Herzog nach Spanien. Noch vor dem Ende des Spanischen Erbfolgekriegs mussten die beiden nach Wien zurückkehren, da Kaiser Joseph I. unerwartet verstorben war und Erzherzog Karl die Nachfolge seines Bruders antrat. Anton Florian selber eilte in den Jahren 1711 bis 1713 von Erfolg zu Erfolg: Er war nun kaiserlicher Obersthofmeister. Aufgrund des Todes seines Neffen Maximilian Anton fiel ihm 1711 das Majorat der Linie Gundaker zu, nach dem Tod von Hans Adam I. 1712 auch das Majorat der Primogenitur. 1713 erreichte er die Zulassung zum Reichsfürstentrat „ad personam “, also für sich, aber nicht für seine Regierungsnachfolger. ${ }^{24}$ Als kaiserlicher Obersthofmeister konnte er aufgrund seiner Position Sitz und Stimme im Reichsfürstenrat auch ohne Besitz eines Reichsfürstentums beanspruchen. Er verwies darauf, dass vor ihm schon andere Obersthofmeister ohne Reichsfürstentum die Zulassung unter ähnlichen Voraussetzungen bekommen hatten. ${ }^{25}$ Der Fürst wurde von Kaiser Karl VI. unterstützt, was für den Erfolg seiner Bemühungen entscheidend war.

Wollten die Liechtenstein Sitz und Stimme im Reichsfürstenrat erhalten, brauchten sie ein Reichsfürstentum, eine Reichsgrafschaft genügte nur für einen Sitz auf der Grafenbank. Mit dem Tausch der Herrschaft Rumburg gegen die Herrschaften Vaduz und Schellenberg im März 1718 wurde der Weg frei, die beiden Herrschaften zum Reichsfürstentum Liechtenstein zu erheben. Diese Erhöhung war für den Status der Familie und für den Rang im Reichsfürstenkollegium wichtig: Ohne die Erhöhung zu einem Reichsfürstentum hätten die Fürsten nur einen Sitz auf der Grafenbank beanspruchen können, wo sie keine eigene Stimme (Virilstimme), sondern nur eine gemeinsame Kuriatstimme zusammen mit Grafen gehabt hätten. Kaiser Karl VI. zeigte sich bereit, auf die Wünsche seines Obersthofmeisters einzugehen. Am 23. Januar 1719 vereinigte er die beiden Landschaften und erhob sie zum Reichsfürstentum Liechtenstein. Gleichzeitig wurden alle Rechte und Privilegien des Hauses Liechtenstein (darunter das Grosse Palatinat) bestätigt. Die „Brandisischen Freiheiten“ (Blutbann und Reichsunmittelbarkeit) waren bereits 1715 dem Fürsten Joseph Wenzel bestätigt worden und wurden 1719 Anton Florian erneut bestätigt.

Nach der Erhebung machte sich Anton Florian daran, die Reichsstandschaft für seine Nachkommen zu sichern, überdies wollte er auch das zinslose Darlehen von 250000

23 In erster Ehe verheiratet mit Graf Johann Ernst von Thun (1694-1717).

24 Arnegger, K.: Session und Votum, S. 105-116.

25 Arnegger, K.: Session und Votum, S. 102. 

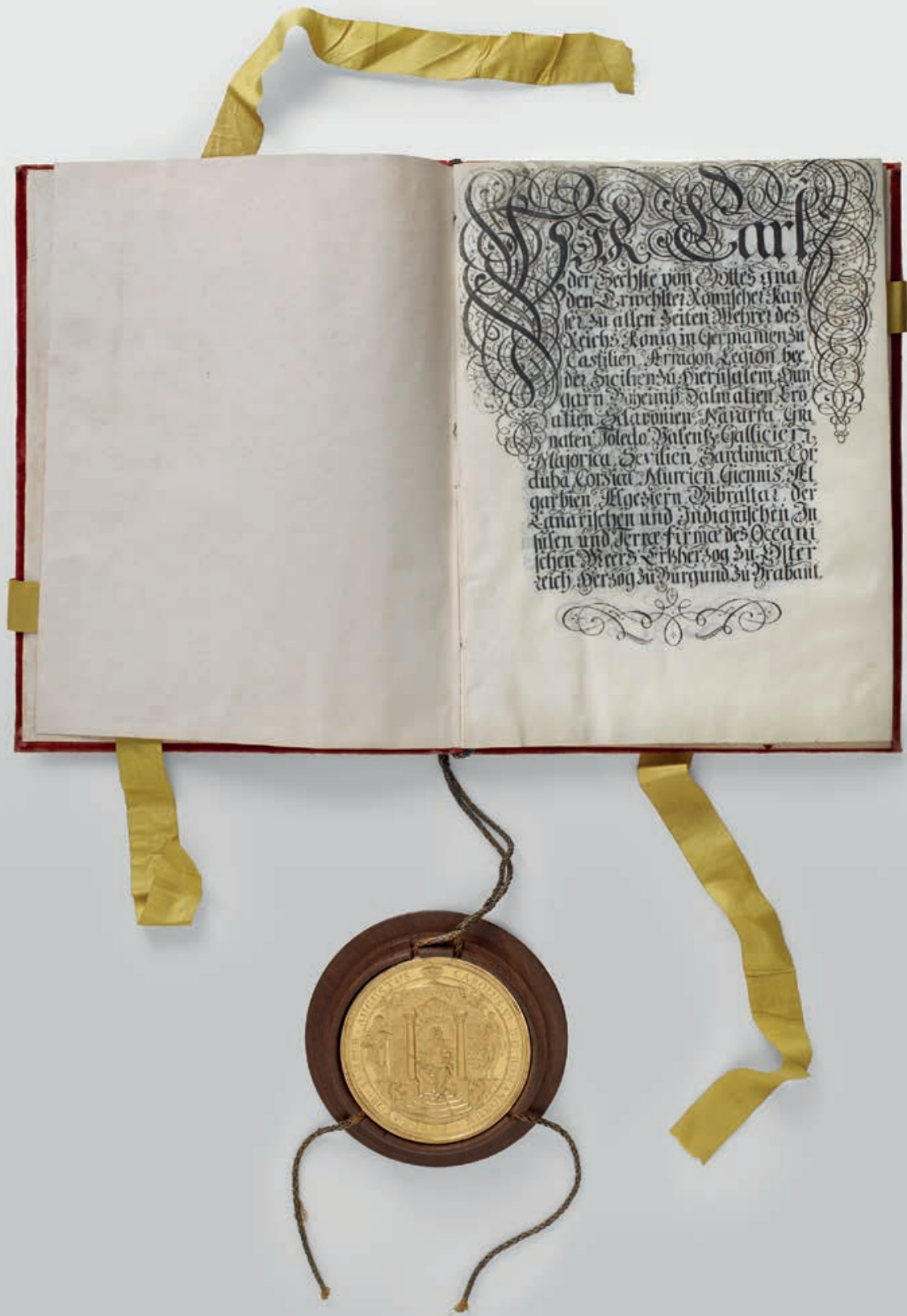

Kaiser Karl VI. vereinigt am 23. Januar 1719 die Grafschaft Vaduz und die Herrschaft Schellenberg und erhebt sie zu einem reichsunmittelbaren Fürstentum mit dem Namens "Liechtenstein”. Ausf. Wien, 1719 Januar 23, AT-HAL, U (Foto: LIECHTENSTEIN. The Princely

Collections Inv. Nr. UR 1719.01.23.1.) 
Gulden zurückbekommen. Die Reichsstände machten ihm aber klar, dass das Fürstentum zu klein war und das reichsunmittelbare Territorium nur zusammen mit diesem Darlehen als reichsfürstenmässiger Besitz anerkannt wurde. Anton Florian erlebte die endgültige Aufnahme des Hauses in den Reichsfürstenrat nicht mehr; 1721 starb er. Sein Nachfolger Josef Johann akzeptierte die Bedingungen des Reichstagskollegiums. Auf dieser Basis wurde 1723 ihm und allen seinen Regierungsnachfolgern die Reichsstandschaft zuerkannt.

\section{Ein neues absolutistisches Regierungssystem}

Die Erhebung zum Reichsfürstentum Liechtenstein war für die Untertanen kein Anlass zum Feiern, sie wurde eher beiläufig zur Kenntnis genommen. Im Gegensatz dazu waren die Huldigungen (1699 und 1712 wurde Johann Adam I., 1718 Anton Florian gehuldigt) als grosse Freudentage inszeniert worden, an denen alle männlichen Untertanen teilnehmen und dem neuen Landesherrn huldigen und Treue schwören mussten. Das ganze Volk sollte mitfeiern und erhielt Wein und Brot.

Die Erhebung zum Reichsfürstentum veranlasste den Fürsten zu radikalen Änderungen der Verfassung und der politischen Strukturen: ${ }^{26}$ Anton Florian sah sich als Reichsfürst von Gottes Gnaden und regierte sein Fürstentum im Sinne des Absolutismus. Er beanspruchte alle Hoheitsrechte und hob die alten Rechte und Gewohnheiten auf, obwohl er mehrfach versichert hatte, die guten alten Rechte beizubehalten. Die beiden Landschaften mit ihren gewählten Landammännern wurden abgeschafft, das Land neu in sechs Ämter eingeteilt. Auf Beschwerden der Untertanen wegen der Aufhebung der alten Gewohnheitsrechte liess er ausrichten, er habe nur die Beibehaltung der guten alten Rechte versprochen, die Beibehaltung von Missbräuchen könne er nicht mit seinem Gewissen vereinbaren. Die Untertanen sollten durch neue Abgaben und höhere Steuern belastet werden, zudem wollte der Fürst ein kleines ständiges Militärkontingent aufstellen. Herrschaftliche Güter, die zum Hohenemser Fideikommiss gehörten, von den Grafen von Hohenems aber nach 1699 an die Gemeinden verkauft worden waren, mussten dem Fürsten zurückgegeben werden. Dem Klerus wurde das Recht auf den Novalzehnt, der traditionellerweise der Kirche zustand, abgestritten.

Diese Reformen führten sowohl bei den Untertanen wie auch beim Klerus zu einem jahrelangen Widerstand. Den Untertanen wurde nicht nur Ungehorsam, sondern Rebellion vorgeworfen und gedroht, Truppen des Schwäbischen Kreises anzufordern, um ihren Widerstand zu brechen. Dem Klerus wurde Anstiftung der Untertanen zu Ungehorsam vorgeworfen. Die Einnahmen der Kirche wurden gesperrt; der Bischof seinerseits exkommunizierte einzelne fürstliche Beamte. Schliesslich wurde der Konflikt durch eine kaiserliche Kommission (bzw. eine solche des Reichshofrats) gelöst, die - soweit es die Untertanen betraf - im Wesentlichen im Sinne des Fürsten entschied. Mit dem

26 Siehe dazu Vogt, Paul: „Wann ein pauer zehen mahl recht hat, darf man ihm gleichwohl nicht recht lassen“. Absolutistische Reformen und Widerstand (1719-1733). Jahrbuch des Historischen Vereins für das Fürstentum Liechtenstein 118, 2019, S. $93-12$. 
Klerus wurde eine einvernehmliche Lösung erzielt: Der Novalzehnt wurde zwischen Kirche und Fürst geteilt. Eine endgültige Regelung des Konflikts mit den Untertanen wurde erst 1733 gefunden, als eine fürstliche Kommission nach Vaduz kam und in einer Art Kompromiss die Wiedereinführung der beiden Landschaften und der Landammänner zugestand - dies jedoch nur der äusseren Form und dem Namen nach, ohne dass die Untertanen daraus Rechte ableiten konnten.

\section{Fazit}

Liechtenstein verdankt die Erhebung zu einem Fürstentum dem zähen Streben der Fürsten von Liechtenstein nach einer Standeserhöhung. Karl von Liechtenstein wurde 1608 in den Fürstenstand und 1620 in den Reichsfürstenstand erhoben. 1623 erhielten auch seine Brüder Maximilian und Gundaker den Reichsfürstentitel - damit waren sie Titularfürsten, sie durften den Titel „Reichsfürsten“ gebrauchen, dieser verschaffte ihnen aber keine neuen Rechte. Ihr Ziel war „Sitz und Stimme“ im Reichsfürstenrat. Die Chancen dazu verschlechterten sich seit dem Reichstag in Augsburg im Jahr 1582 zunehmend. Einerseits erschwerten die „Altfürsten“ die Zulassung von „Neufürsten“, andererseits hinderte der „Liechtenstein-Prozess“ die Fürsten in ihren Bemühungen. Erst nachdem dieser Prozess 1665 durch einen Vergleich geregelt worden war und sich das Haus auch wirtschaftlich wieder erholt hatte, konnten diese Bestrebungen wieder aufgenommen werden.

Die Grafschaft Vaduz und die Herrschaft Schellenberg waren seit dem Mittelalter reichsunmittelbare Lehen, ihre Besitzer hatten die Reichsstandschaft (d.h. Sitz und Stimme im Reichstag). Nachdem die Liechtenstein verschiedene andere Projekte zum Erwerb einer reichsunmittelbaren Herrschaft nicht hatten realisieren können, ermöglichte der Kauf der beiden Herrschaften doch noch, zu Sitz und Stimme im Reichstag zu kommen. 1699 kaufte Fürst Hans Adam I. die Herrschaft Schellenberg. Da diese allein zu klein war, einigte er sich 1707 mit dem Schwäbischen Kreis darauf, die fehlende Grösse durch ein unverzinsliches Darlehen von 250`000 Gulden an den Schwäbischen Reichskreis zu kompensieren. Dies brachte ihm vorerst nur einen Sitz auf der Fürstenbank des Schwäbischen Kreises. 1712 kauft er auch die Grafschaft Vaduz.

Fürst Hans Adam I. erlebte die Aufnahme in den Reichsfürstenrat nicht mehr, kurz nach dem Kauf von Vaduz starb er. Aufgrund des Testaments ergaben sich neue Probleme: Anton Florian hatte Vaduz und Schellenberg nicht dem neuen Oberhaupt der Familie - dem Fürsten Anton Florian - vermacht, sondern dem unmündigen Josef Wenzel, einem Neffen dritten Grades. Anton Florian war sofort bemüht, Vaduz und Schellenberg wieder in den Besitz der Hauptlinie zu bringen. Dies gelang ihm 1718 durch einen Tausch der Herrschaft Rumburg gegen Vaduz und Schellenberg.

Fürst Anton Florian von Liechtenstein war eine der einflussreichsten Persönlichkeiten am kaiserlichen Hof. Er war „Erzieher“ von Kaiser Karl VI. und nahm als kaiserlicher Obersthofmeister die wohl wichtigste Position unter den Beamten am kaiserlichen Hof ein. 1713 erreichte er die Zulassung in den Reichsfürstenrat „ad personam“, also für sich, 
aber nicht für seine Nachkommen. Auf seine Bitte erhob Kaiser Karl VI. 1719 die beiden Herrschaften zum Reichsfürstentum Liechtenstein. Anton Florian starb 1721, noch bevor er die Reichsstandschaft für seine Nachfolger sichern konnte. Dieser letzte Schritt auf dem Weg zu Sitz und Stimme im Reichsfürstenrat war seinem Sohn und Nachfolger Josef Johann Adam vorbehalten: Er sicherte sich und seinen Nachfolgern 1723 die Zulassung in den Reichsfürstenrat. Das Haus Liechtenstein gehörte damit zum vornehmsten Adel in Wien und im Reich.

\section{Resumé}

\section{Jak vzniklo Lichtenštejnské knížectví}

Dne 23. ledna 1719 spojil císař Karel VI. na přání knížete Antonína Floriána Vaduz a Schellenberg, dvě panství podléhající přímo císaři, do jednoho ř́̌šského knížectví pod názvem „Lichtenštejnsko“. Knížata z Lichtenštejna se tak ocitla těsně před svým cílem: jako držitelé říšského knížectví měla nárok na křeslo na sněmu řišských knížat v Řezně. Připuštěním na sněm řišských knížat obdržela nejvyšší postavení, jaké mohla v říši získat. O zemi a lidi ve svém malém knížectví se moc nezajímala. Kníže z Lichtenštejna navštívil své knížectví poprvé až v roce 1842.

Povýšení obou panství na říšské knížectví předcházela dlouhá historie. Počátkem 17. století konvertovali kníže Karel a jeho bratři Maxmilián a Gundakar ke katolické víře a otevřeli si tak cestu k mimořádným kariérám ve službách císařů Rudolfa II., Matyáše a Ferdinanda II. Karel a Gundakar byli jmenováni do nejdůležitějších úřadů na císařském dvoře včetně úřadu nejvyššího hofmistra. Kníže Karel byl znám tím, že dokázal využít př́ležitosti a sloužit věrně císaři a současně získávat ve vlastním zájmu tituly, hodnosti a majetky. Za své služby byl bohatě odměněn: v roce 1608 získal dědičný knížecí titul a v roce 1620 titul říšského knížete. Karel a jeho bratři položili základní kámen fenomenálního vzestupu lichtenštejnského rodu.

Titul ř́ršského knížete, který Lichtenštejnové obdrželi, byl titulem titulárním - Lichtenštejnové byli ř́ršskými knížaty bez ř́̌šského knížectví. Nebyli jediní, koho císař počátkem 17. století tímto titulem odměnil. „Stará knížata“ se „novými knížaty“ cítila ohrožena ve svém postavení a bránila tomu, aby „nová knížata“, která nedisponovala žádným územím podléhajícím bezprostředně císaři, získala křeslo a hlas na říšském sněmu.

Pokud chtěli Lichtenštejnové tohoto cíle dosáhnout, neměli jinou možnost, než nějaké teritorium podléhající bezprostředně císaři nabýt. To nebylo ani tak otázkou peněz jako spíše nabídky a v konečném důsledku i podpory ze strany císaře. O získání takového území usiloval už kníže Gundakar. Nenašel však vhodný objekt. Zemřel v roce 1658. Jeho synovec Karel Eusebius se zabýval jinými problémy a o získání území podléhajícího bezprostředně císaři se nikdy příliš nesnažil.

Na tyto snahy navázal až jeho syn Jan Adam I. Konkrétně se jednalo o koupi panství Vaduz a Schellenberg. Jejich držitelé, hrabata z Hohenemsu, byli velmi zadlužení a museli svá panství prodat. K prodeji bylo zapotřebí jak souhlasu rodu, tak i císaře, protože obě území náležela k hohenemskému fideikomisu. Realizace tohoto složitého obchodu trvala více než 20 let. V roce 1699 se knížeti Janu Adamovi I. podařilo koupit nejprve pouze panství Schellenberg, na hrabství Vaduz bylo sjednáno předkupní právo. 
Prvním krokem před připuštěním na sněm říšských knížat bylo připuštění na švábský krajský sněm. Při tom se objevily nové překážky: hrabata z Hohenemsu si sice nárokovala dvě místa na lavici hrabat na sněmu Švábského kraje (jedno za hrabství Hohenems, druhé za hrabství Vaduz), tento nárok však nikdy nedokázala prosadit. Samotné panství Schellenberg bylo př́iliš malé na to, než aby jím bylo možné odůvodnit místo na lavici knížat na sněmu Švábského kraje. Východisko z této situace bylo nalezeno tak, že kníže Jan Adam poskytl v roce 1707 zadluženému říšskému kraji bezúročnou půjčku ve výši 250000 zlatých, a tím vyrovnal deficit příliš malého území.

Dne 22. března 1712 podepsal kníže Jan Adam I. kupní smlouvu na hrabství Vaduz, o několik málo týdnů později však zemřel. Ve své závěti odkázal nově získaná panství Vaduz a Schellenberg knížeti Josefu Václavovi (čímž pominul knížete Antonína Floriána). Tato závět neškodila jen Antonínu Floriánovi osobně, ale byla rovněž v rozporu se zájmy celého lichtenštejnského rodu. Antonín Florián ji soudně napadl, ale v roce 1718 se s Josefem Václavem dohodl na následující směně: Antonín Florián obdržel Vaduz a Schellenberg, Josef Václav panství Rumburk v Čechách. Smír v rodině byl navíc zajištěn i sňatkem Josefa Václava s Annou Marií, dcerou Antonína Floriána.

Antonín Florián byl nejvyšším hofmistrem císaře Karla VI., díky tomuto postavení, byl už v roce 1713 připuštěn na sněm řŕšských knížat v Řezně. Právo účasti na sněmu ale bylo omezeno jen na jeho osobu; jeho následovníci si z toho nemohli odvozovat žádné nároky. Díky dobrým vztahům s císařem Karlem VI. dosáhl Antonín Florián v roce 1719 povýšení obou zmíněných panství podléhajících bezprostředně císaři na říšské knížectví. Na základě této držby pak uplatnil nárok na připuštění na sněm řišssých knížat i pro své následovníky. Jejich připuštění na sněm se však Antonín Florián už nedožil, zemřel v roce 1721. Souhlas se podařilo na dlouho se zdráhajícím sněmu vyvzdorovat až jeho nástupci Josefu Janu Adamovi, a to tvrdošíjností, mnoha dary a diplomatickým umem. 


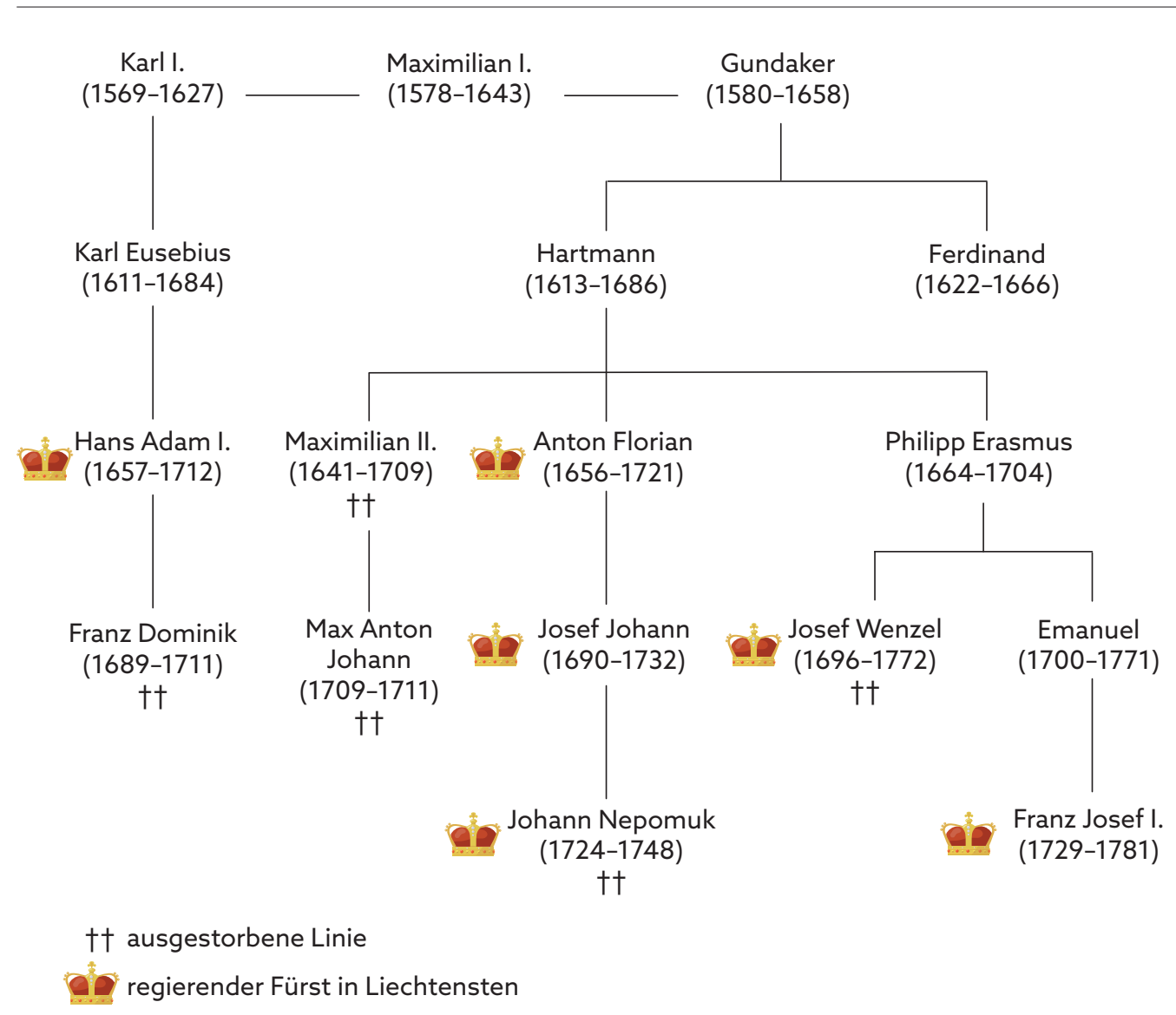

Stammbaum der Fürsten von Liechtenstein 
